\title{
Efetividade da assistência estudantil para garantir a permanência discente no ensino superior público brasileiro
}

\author{
Effectiveness of student assistance to ensure \\ student permanence in Brazilian public higher education
}

\author{
Sandy Andreza de Lavor Araújo ${ }^{1}$ \\ ${ }^{1}$ Instituto Federal do Ceará | Departamento de Apoio Estudantil \\ Fortaleza | CE | Brasil. Contato: sandyandreza@ hotmail.com \\ http://orcid.org/0000-0002-1959-4772
}

Wagner Bandeira Andriola ${ }^{2}$
${ }^{2}$ Universidade Federal do Ceará | Faculdade de Educação
Fortaleza | CE | Brasil. Contato: w_andriola@ @ahoo.com
http://orcid.org/0000-0001-6459-0992

Sueli Maria de Araújo Cavalcante ${ }^{3}$

${ }^{3}$ Universidade Federal do Ceará | Faculdade de Educação

Fortaleza | CE | Brasil. Contato: suelicavalcante@ufc.br

http://orcid.org/0000-0002-0698-2485

\author{
Denise Maria Moreira Chagas Corrêa ${ }^{4}$ \\ ${ }^{4}$ Universidade Federal do Ceará | Faculdade de Educação \\ Fortaleza | CE | Brasil. Contato: denisecorrea@ufc.br \\ http://orcid.org/0000-0001-7914-6982
}

Resumo: Este estudo se propôs a apresentar o impacto da implantação da assistência estudantil sobre a permanência no ensino superior público brasileiro, no IFCE campus Iguatu, durante o período 2011 a 2015. Caracterizou-se por uma abordagem quanti-qualitativa, de caráter exploratório-descritivo. Empregaram-se pesquisas documental e de campo, consoante as normas que regulam a Assistência Estudantil, no sistema acadêmico e no setor de Serviço Social. Os resultados indicaram maior permanência entre os estudantes beneficiários dos auxílios estudantis, quando comparado aos não beneficiários; maior taxa de permanência entre estudantes do sexo feminino em comparação aos do sexo masculino; o curso de Bacharelado em Serviço Social possui maior taxa de permanência discente, enquanto o curso de Tecnologia em Irrigação e Drenagem obteve a menor taxa de permanência discente. A pesquisa aponta que os auxílios pecuniários, um dos mecanismos da Política de Assistência Estudantil, são uma possibilidade efetiva de garantia da permanência estudantil no ensino superior.

Palavras-chave: Ensino superior. Avaliação educacional. Permanência estudantil. Assistência estudantil.

Abstract: This study aimed to present the impact of the implementation of student assistance on the stay in Brazilian public higher education at the IFCE campus Iguatu, during the period from 2011 to 2015. It was characterized by a quantitative-qualitative, exploratory-descriptive approach. As for the employed techniques, documentary and field research was carried out, in the norms that regulate Student Assistance, in the academic system and in the Social Service sector. The results indicated a greater permanence among the student beneficiaries of the student aid when compared to the non-beneficiaries; higher length of stay among female students compared to males; the course of Bachelor of Social Service has a higher rate of student stay, while the course in Technology in Irrigation and Drainage obtained the lowest rate of student stay. The research point out that financial aid is an effective possibility to guarantee student stay in higher education.

Key words: Higher education. Educational evaluation. Student stay. Student assistance. 
DOI: http://dx.doi.org/10.1590/S1414-40772019000300009

Este é um artigo publicado em acesso aberto sob uma licença Creative Commons https://creativecommons.org/licenses/by-nc/4.0/

\section{Introdução}

Políticas voltadas à garantia da permanência discente no ensino superior vêm sendo cada vez mais requisitadas e implementadas com vistas a apoiar a expansão e a interiorização desse nível educacional no Brasil (ARAÚJO; ANDRIOLA; COELHO, 2018). Essa expansão tem se dado por meio de três programas e, dentre eles, dois possuem o foco na expansão a partir da iniciativa privada - Programa Universidade para Todos (PROUNI) e o Fundo de Financiamento Estudantil (FIES) -, e outro tem o foco na expansão a partir das Instituições de Ensino Superior Públicas - o Programa de Apoio a Planos de Reestruturação e Expansão das Universidades Federais (REUNI).

Com a preocupação de garantir a permanência no ensino superior público e o sucesso acadêmico dos discentes, em 2007 foi publicada a portaria no 39 do Ministério da Educação, ampliada e alterada pelo decreto $\mathrm{n}^{\circ} 7234 / 2010$, que reorganizou e ampliou o Programa Nacional de Assistência Estudantil (PNAES), com o objetivo de disciplinar a oferta de Assistência Estudantil nas Instituições Federais de Ensino Superior Públicas.

A principal finalidade do PNAES é ampliar as condições de permanência dos jovens na educação superior pública federal, a partir da democratização das condições de permanência; da minimização dos efeitos das desigualdades sociais e regionais na permanência e conclusão da educação superior; da redução das taxas de evasão e retenção; e da contribuição para a promoção da inclusão social pela educação (BRASIL, 2010). É um programa nacional que indica as diretrizes a serem adotadas internamente pelas Instituições de Ensino Superior Públicas, as quais organizam a assistência estudantil sob a forma de políticas compostas por programas e serviços, constituindo-se num conjunto de ações direcionadas a garantir a permanência e o sucesso acadêmico.

A "assistência estudantil" constitui-se como "a organização de serviços de apoio discente ou iniciativas que busquem democratizar o acesso ao ensino e favorecer a permanência do estudante no contexto escolar" (RAMALHO, 2013, p. 23). 
Consoante Dumaresq (2014, p. 45), a Assistência Estudantil destina-se a proporcionar as "ideais condições de saúde, acesso aos instrumentais necessários à formação profissional, até o provimento dos recursos mínimos necessários para aos estudantes, tais como moradia, alimentação, transporte e recursos financeiros para outros gastos”.

Acerca da criação dos Institutos Federais, Otranto (2013, p. 122) ressalta que "a Lei 11.892/08 redesenhou a rede federal de educação profissional, deu novos contornos não somente à educação profissional, mas também à educação superior como um todo". A criação dos Institutos Federais ocorreu a "partir da agregação de instituições de educação profissional da rede federal, tais como: Centros Federais de Educação (CEFETs), Escolas Agrotécnicas Federais (EAFs) e Escolas Vinculadas às Universidades Federais (EVs) (p. 123)”, passando a ofertar cursos tecnológicos, de licenciaturas e bacharelados.

O Instituto Federal do Ceará (IFCE), campus Iguatu, antiga Escola Agrotécnica Federal, desde 2011, implementa institucionalmente ações de Assistência Estudantil preconizadas no PNAES, embora a regulamentação interna da Política de Assistência Estudantil tenha sido aprovada apenas em 2014, a partir da Resolução 008/2014 do Conselho Superior (CONSUP) do IFCE.

Ante a ampliação dos ingressos de alunos economicamente hipossuficientes, e em face do processo de expansão e interiorização do ensino superior, iniciado com o REUNI (ANDRIOLA; SULIANO, 2015), a indagação que se fez para ser respondida através da pesquisa foi: qual o impacto da implantação da assistência estudantil sobre a permanência no ensino superior público brasileiro, tendo em vista o contexto da interiorização no caso do IFCE no campus Iguatu, durante o período de 2011 a 2015 ?

Neste contexto, o trabalho objetivou descrever a realidade da permanência estudantil no ensino superior no IFCE campus Iguatu, a partir da realidade dos estudantes usuários do programa de auxílios pecuniários da Política de Assistência Estudantil. De acordo com Andrade e Teixeira (2017) existe uma lacuna de estudos que avaliem o impacto das dez áreas propostas pelo PNAES para combater a retenção e a evasão e promover a inclusão social, fato que realça a relevância da presente pesquisa.

O estudo realizou um diagnóstico da realidade da Política de Assistência do IFCE tomando como referência o campus Iguatu, tendo em vista a dificuldade significativa de analisar a realidade de todos os campi do IFCE, dada a vasta heterogeneidade de realidades de cada campus. Além disso, o referido campus é um dos maiores do Estado do Ceará, em termos de orçamento, sendo um dos mais antigos da rede federal cearense. 
Convém destacar, ademais, que o uso das informações decorrentes do estudo torna-se vital para os gestores educacionais, posto que o propósito de toda e qualquer sistemática avaliativa é fornecer subsídios para que os responsáveis pela coordenação e planejamento de ações educativas possam tomar decisões visando o seu aperfeiçoamento (ANDRIOLA, 1999; 2005).

Como objetivos específicos do estudo, delinearam-se: i) descrever o contexto do ingresso e permanência no ensino superior no IFCE, campus Iguatu, no período de 2011 a 2015; ii) identificar a taxa de ingresso e permanência por sexo, curso, e condição de beneficiário ou não beneficiário dos auxílios transporte, discente pai/mãe e moradia; e iii) estabelecer um comparativo entre a taxa de permanência entre beneficiários dos auxílios moradia, transporte e discente pai/mãe e não beneficiários.

Três cursos superiores do IFCE campus Iguatu foram analisados: Licenciatura em Química, Bacharelado em Serviço Social e Tecnologia em Irrigação e Drenagem. Considerando-se a quantidade de oito auxílios pecuniários ofertados pelo campus (Auxílio Moradia, Auxílio Transporte, Auxílio Discente Pai/Mãe, Auxílio Óculos, Auxílio Formação, Auxílio Acadêmico, Auxílio Visitas e Viagens Técnicas e Auxílio Pré-Embarque internacional), a pesquisa abrangeu os três primeiros, respectivamente.

A escolha desses auxílios para a pesquisa se deve ao fato de terem o caráter contínuo, ao longo da formação do discente; por serem os únicos auxílios com maior banco de informações físicas passíveis de análise; por que tem maior em número de estudantes beneficiários, ficando atrás somente, do número de beneficiários do serviço de alimentação, que apesar de ser o maior, não dispõe de informações sistematizadas, passíveis de análise durante a presente pesquisa.

Este estudo delineou-se pela perspectiva dialética, em função de ser esta a perspectiva que, constituindo processo reflexivo, concebe a realidade como o conjunto complexo de fatos interrelacionados e em constante movimento (MARCONI; LAKATOS, 2010). Além disso, esse estudo é caracterizado por uma abordagem quanti-qualitativa, realizada a partir de um estudo de caráter exploratório-descritivo que recorreu à pesquisa documental, tendo como objeto as normas que regulam a Assistência Estudantil em âmbito nacional, regional e local, bem como, bem como pesquisa de campo, no âmbito do sistema acadêmico e no setor de Serviço Social do campus.

O conceito adotado de permanência considerou os estudantes que no sistema acadêmico do IFCE encontravam-se, até setembro de 2017, como matriculado, concludente e egresso. Para o conceito de não-permanência, foram considerados os estudantes que, até o mesmo mês e ano 
anteriormente mencionados encontravam-se com o status de matrícula cancelada, abandonada ou trancada.

A partir dessa categorização realizou-se análise comparativa entre os beneficiários dos três principais tipos de auxílios no período de 2011 a 2015, em relação à realidade geral dos estudantes não beneficiários.

\section{A Política de Assistência Estudantil do IFCE: estrutura e organização}

É necessário problematizar que a Assistência Estudantil, como política pública, constitui-se numa oportunidade real para a expressiva maioria de estudantes ter acesso às condições de permanência, diante das inúmeras necessidades advindas do ingresso no curso. Sobre essa necessidade, Souza (2017, p. 138) afirma que:

A defesa da assistência estudantil, como política social pública, vai contra a sua apropriação como política de governo, submetida ao bel-prazer de governantes que implementam o que querem, como querem, ou mesmo anulam seu potencial de viabilizar direitos.

Dada a correlação elevada entre pobreza e desigualdade social no Brasil, é possível conceber a Assistência Estudantil como uma "política inclusiva, na medida em que pode atuar no sentido de ampliar as oportunidades de permanência de grupos historicamente discriminados por questões de cor/raça, por exemplo" (PINTO, 2015, p. 28).

Nesse âmbito o Instituto Federal do Ceará (IFCE), desde 2011, conta com programas e serviços de Assistência Estudantil que vem sendo afirmados e garantidos mediante legislações como a Política de Assistência Estudantil do IFCE e o Regulamento de Auxílios Estudantis, legislações estas que disciplinam a oferta de serviços, programas, projetos e ações de Assistência Estudantil nos campi da instituição.

A política de assistência estudantil, embora não possa prescindir da questão
financeira, deve ser trabalhada em consonância com os aspectos pedagógicos e
psicossociais, ou seja, com suporte em uma política pública de assistência estudantil
não apenas voltada para a subsistência material, mas também preocupada com as
questões emocionais, pensando a pessoa como um todo (DUMARESQ, 2014, p. 45).

Após a aprovação da Resolução no 008/2014, no âmbito do Instituto Federal do Ceará, a qual dispunha sobre os programas, serviços, projetos, ações e assistência estudantil a serem ofertadas pela instituição, houve o desmembramento desta norma em duas resoluções: a Resolução nº 024, de 22 de junho de 2015, a qual aprovou a Política de Assistência Estudantil do IFCE e a Resolução $n^{\circ}$ 052, de 24 de outubro de 2016, a qual aprovou o Regulamento de 
Concessão de Auxílios Estudantis no IFCE. Assim, o campus de Iguatu tem sua política de Assistência Estudantil baseada nas resoluções retro citadas.

A Política de Assistência Estudantil do IFCE compreende as diretrizes, objetivos e princípios que compõem a oferta dos serviços, programas, projetos e ações. Em seu artigo $1^{\circ}$ a parágrafo único afirma que a política de assistência estudantil da instituição destina-se a todos os estudantes regularmente matriculados no sistema acadêmico, entretanto, o art. 13 da mesma resolução acrescenta que se constitui como público alvo os estudantes matriculados e prioritariamente em situação de vulnerabilidade. É perceptível que o regulamento não define o tipo de vulnerabilidade nem tampouco define o conceito de vulnerabilidade social adotado. De acordo com Souza (2017, p. 142):

Constata-se que a realidade dos estudantes-alvo da assistência estudantil, é fruto, para além de outros condicionantes, do processo de desestruturação das relações de trabalho, que tem conduzido um elevado contingente populacional ao desemprego ou à submissão a relações laborais precarizadas para sobreviverem. Com efeito, os Institutos Federais têm trabalhado, no tocante a esta política, com o conceito de pobreza relativa, que considera pobres aqueles, que em relação ao conjunto da população, ganham um salário inferior ao mínimo, ou até um salário mínimo e meio per capita. .

A partir de dados do Tribunal de Contas da União (TCU), Souza (2017) afirma que é perceptível que os institutos federais contam com uma realidade de um perfil extremamente heterogêneo em relação à faixa etária e renda, pois a inserção sócio-territorial desses institutos faz-se predominantemente em localidades de municípios com baixo Índice de Desenvolvimento da Educação Básica (IDEB) e alto índice de pobreza. Segundo Souza (2017, p. 131):

Tal fato apresenta-se como um grande desafio aos Institutos Federais, posto que, no Brasil, a oferta de uma educação gratuita e de qualidade à classe trabalhadora não constitui, na prática, um direito de todos, como prevê a Constituição da República. Ou seja, a oferta da educação gratuita reflete a própria composição desigual da sociedade brasileira ao longo da sua história. Portanto, pela educação, é necessário incluir socialmente um grupo de indivíduos - que não é minoria - no interior da escola, cujas questões ultrapassam o processo de ensino e aprendizagem, ao mesmo tempo em que integram este processo.

De acordo com o Regulamento da Política de Assistência Estudantil do IFCE (2015), constituem-se como princípios de sua política de assistência estudantil, os seguintes: art. $2^{\circ}$, I respeito à liberdade e à dignidade humana; II - educação e assistência estudantil como um direito social e universal; III - participação ampliada dos sujeitos nos processos de construção dos programas e projetos institucionais; IV - valorização das condições de permanência, êxito e conclusão de curso dos estudantes do ensino técnico e superior, mediante serviços e/ou auxílios; V - equidade na prestação dos serviços educacionais, visando ao acesso, a permanência e o êxito acadêmico. 
O regulamento em questão traça as onze diretrizes que seguem: art. $3^{\circ}$, I - oferta de educação pública, gratuita, laica e de qualidade; II - criação de mecanismos de participação e controle social; III - participação do estudante por meio de suas organizações representativas, na formulação, implementação e avaliação dos planos, programas e projetos a serem desenvolvidos; IV - promoção da intersetorialidade entre as diferentes políticas sociais; V formação de espaços de diálogo entre família, escola e comunidade; VI - valorização de uma educação em saúde, em prol da qualidade de vida; VII - integralidade e qualidade nos serviços prestados pela instituição; VIII - incentivo às manifestações culturais no ensino, pesquisa e extensão; IX - combate a todas as formas de preconceito e discriminação; X - promoção do acesso ao esporte, cultura e lazer nos diferentes níveis; XI - realização de avaliação e/ou pesquisa para subsidiar o planejamento e execução das ações (IFCE, 2015).

Além dos objetivos definidos pelo PNAES, o Regulamento da política de assistência estudantil do IFCE acrescenta como seus objetivos, no artigo $4^{\circ}$, I - incentivar a participação da comunidade do IFCE em ações voltadas à sustentabilidade e à responsabilidade social; III ampliar as condições de participação democrática, para formação e o exercício de cidadania visando à acessibilidade, à diversidade, ao pluralismo de ideias e à inclusão social; IV promover o acesso universal à saúde, ancorado no princípio da integralidade, reunindo ações e serviços de acordo com a realidade local, de modo a fortalecer a educação em saúde; V contribuir para a inserção do aluno no mundo do trabalho, enquanto ser social, político e técnico (IFCE, 2015).

De acordo com o Regulamento, os serviços postos à disposição dos estudantes são constituídos pelo Serviço Social, o Serviço de Psicologia, o Serviço de Saúde, o Serviço de Alimentação e Nutrição e pelo Serviço Pedagógico, todos com o objetivo de garantir a permanência e o sucesso escolar dos estudantes (IFCE, 2015).

O Regulamento trata ainda dos programas ofertados no âmbito da política de assistência estudantil do IFCE, que podem possuir caráter universal, ou seja, serem destinados a todos os estudantes, e podem ter caráter específico, no caso daqueles que sejam destinados a um público específico de estudantes, como por exemplo, estudantes em baixas condições socioeconômicas. Os programas dividem-se em cinco áreas, os quais se configuram como programas nas áreas de Trabalho, Educação e Cidadania; Saúde; Alimentação e Nutrição; Cultura, Arte, Desporto e Lazer; Auxílios em Forma de Pecúnia.

Os auxílios estudantis constituem um dos programas da Política de Assistência Estudantil do IFCE e têm como público-alvo os estudantes regularmente matriculados com frequência mínima de $75 \%$ nos cursos ofertados pelo IFCE, tanto no nível superior como no 
nível técnico, sendo classificados em Auxílios ao Estudante em Situação de Vulnerabilidade Social e Auxílios Universais (IFCE, 2016),de acordo com os parágrafos $1^{\circ}$ e $2^{\circ}$ do art. $5^{\circ}$ do Regulamento para Concessão de Auxílios no âmbito do IFCE (IFCE, 2016):

Os Auxílios ao Estudante em Situação de Vulnerabilidade Social serão concedidos com o objetivo de garantir a igualdade de permanência dos estudantes considerados vulneráveis socialmente, que se encontrem em situação de desproteção, insegurança, riscos e instabilidade relacionadas à pobreza, ao pertencimento espacial, étnico-racial, social e cultural impeditivas do acesso aos direitos sociais, aos serviços sociais básicos e aos bens materiais e culturais.

\$2 $2^{\circ}$ Os Auxílios Universais serão destinados aos discentes matriculados nas modalidades especificadas no art. $4^{\circ}$, independente de situação socioeconômica, visando à formação integral do estudante e ao aprimoramento de valores de cidadania, participação, coletividade e inclusão social.

Os auxílios destinados aos estudantes em vulnerabilidade social baseiam-se em critérios específicos de acesso a partir das condições de renda. Logo, é notório que a Assistência Estudantil do IFCE detém ao mesmo tempo o caráter focalizado e universal.

\section{Ingresso e permanência no ensino superior do IFCE campus Iguatu 2011 a 2015}

O ingresso no ensino superior representou ao longo dos anos 2000 um processo de crescente ampliação quanto ao número de vagas, embora a permanência desses ingressantes esteja historicamente comprometida por condições sociais e econômicas desiguais pelas quais passam a significativa maioria da população brasileira.

[...] uma sociedade de formação social desigual, como a brasileira, a dificuldade de permanecer na escola ou a evasão escolar, antes configurar "vagabundagem" de quem não quer estudar, encontra explicação na condição de classe do aluno desertor; isto é, daquele estudante que se encontra privado, ou precariamente provido, dos meios de sobrevivência para sua manutenção, como alimentação, moradia, saúde. Por isso, são sobre estas condições que esta política procura desenvolver ações de inclusão (SOUZA, 2017, p. 132).

Andriola e Suliano (2015) destacaram que a partir de 2003, o Brasil testemunhou uma revolução silenciosa na educação, sobretudo no nível superior. Inicialmente, houve a criação do Sistema Nacional de Avaliação da Educação Superior (SINAES), que estabeleceu marcos regulatórios para as novas IES e seus cursos, com o intuito de garantir padrões mínimos de qualidade, a partir de princípios democráticos, contribuindo, assim, com a expansão da educação superior (ANDRIOLA, 2008).

Para Dias Sobrinho (2010), a "democratização da educação superior não se limita à ampliação de oportunidades de acesso e criação de mais vagas", pois "além da expansão das matrículas e da inclusão social de jovens tradicionalmente desassistidos, em razão de suas 
condições econômicas, preconceitos e outros fatores" é necessário que lhes sejam garantidos os "meios de permanência sustentável", ou seja, que lhes sejam asseguradas "condições adequadas para realizarem com boa qualidade os seus estudos" (DIAS SOBRINHO, 2010, p. 4). Assim, acesso e permanência são aspectos essenciais do processo mais amplo de "democratização". Conforme opinou Lorenzet (2017, p. 63)

[...] a democratização da educação é uma necessidade, assim, com a expansão e a interiorização, por meio destes processos, novas oportunidades de acesso estão sendo construídas, cujo resultado visa em última instância aprimorar a oferta do serviço público na área educacional.

Silva Filho et al. (2007, p. 645) ressaltam que o abandono no ensino superior, "é um problema internacional que afeta o resultado dos sistemas educacionais. As perdas de estudantes que iniciam porém não terminam seus cursos, constituem casos de desperdícios sociais, acadêmicos e econômicos". Pinto (2015, p. 66) corrobora com esta opinião afirmando que:

Para os estudantes oriundos das camadas mais pobres, somente o ingresso, em muitos casos, não se faz suficiente para a conquista da diplomação, tendo em vista que os diversos custos com a escolarização universitária poderão representar um "peso" no orçamento individual e/ou familiar, que eles podem não conseguir corresponder.

Nesse contexto, o total de ingressantes nos cursos de graduação do IFCE, campus de Iguatu, por semestre, é revelado através dos dados da Tabela 1.

Tabela 1 - Total de ingressos na graduação do IFCE campus Iguatu, por semestre (2011 a 2015)

\begin{tabular}{ccccc}
\hline \multirow{2}{*}{ Ano } & \multicolumn{5}{c}{ Quantidade } & Taxa de Variação \\
\cline { 2 - 5 } 2011 & 106 & 83 & 189 & $-21 \%$ \\
\hline 2012 & 104 & 103 & 207 & $-1 \%$ \\
\hline 2013 & 120 & 108 & 228 & $-10 \%$ \\
\hline 2014 & 96 & 72 & 168 & $-25 \%$ \\
\hline 2015 & 119 & 99 & 218 & $-16,8 \%$ \\
\hline Total & $\mathbf{5 4 5}$ & $\mathbf{4 6 5}$ & $\mathbf{1 . 0 1 0}$ & \\
\hline
\end{tabular}

Fonte: Sistema Acadêmico (Q-Acadêmico) do IFCE campus Iguatu, 2018.

A Tabela 1 mostra que em todos os períodos analisados houve decréscimo nos ingressos no segundo semestre letivo do ano acadêmico, sendo que a menor taxa de variação de ingresso ocorreu em 2012. Nos demais anos analisados, o valor médio rondou 18\% de variação negativa, isto é, ingressaram menos alunos nos segundo semestres letivos. 
Observou-se também que o semestre com maior número de ingressos é o semestre 2013.1, com 120 ingressos, e o com menor número ocorreu no semestre 2014.2, com apenas 72 ingressos. Para averiguar-se a proporção de ingresso de homens e mulheres, criou-se a Taxa Geral de Ingresso por Sexo (TGIS), que é composta a partir da relação entre a quantidade de ingressantes do sexo feminino ou masculino e o total de estudantes ingressantes de ambos os sexos. A Taxa Geral de Permanência por Sexo (TGPS) é calculada a partir da quantidade de estudantes do sexo feminino ou masculino que permaneceram em relação ao total de estudantes dos sexos masculino ou feminino que ingressaram, respectivamente para cada um dos gêneros. A Taxa Geral de Permanência Entre os Sexos (TGPES) leva em consideração o total de estudantes do sexo feminino/masculino que permaneceram em relação ao total de estudantes de ambos os sexos que ingressaram.

\section{Gráfico 1 - Taxa de Ingresso e Permanência na graduação do campus Iguatu, por sexo, de 2011/2015}

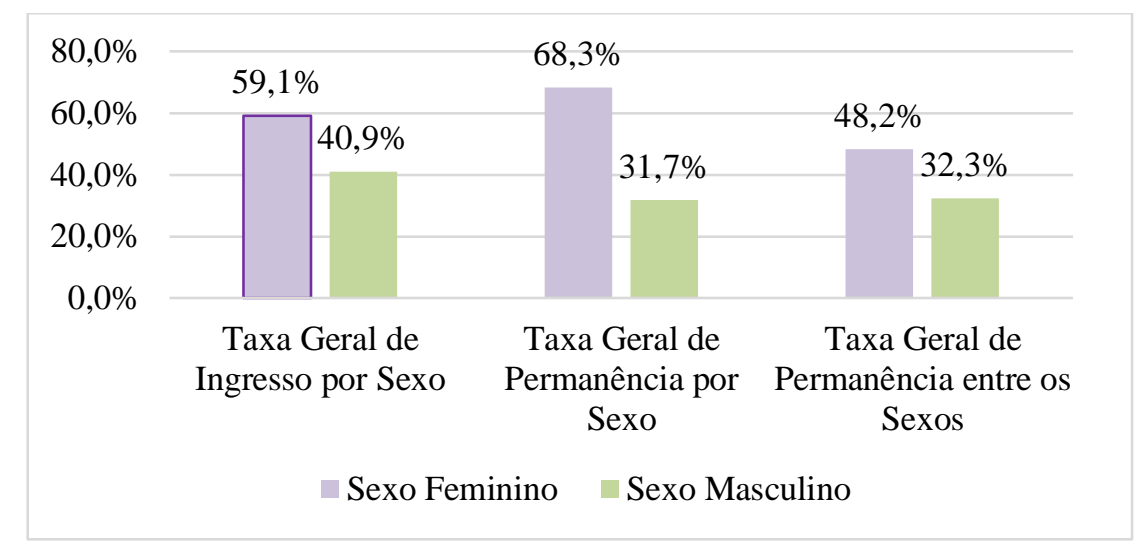

Fonte: Elaborado pelos autores. Dados disponíveis no Q-Acadêmico do IFCE, 2018.

O Gráfico 1 revela que no período analisado houve maior ingresso de mulheres do que de homens, com 59,1\% e 40,9\% respectivamente, designando uma diferença de 18,2\% de maior ingresso de estudante do sexo feminino. O mesmo gráfico indica que no período analisado do total de estudantes que permaneceram, mais de $2 / 3$, (68,3\%), são do sexo feminino, e 31,7\% são do sexo masculino. A maior taxa de permanência foi entre o sexo feminino, pois, do total de mulheres que ingressaram houve permanência em torno de $48,2 \%$, enquanto que entre os homens essa permanência foi de 32,3\%. Observou-se, portanto, a tendência de haver maior 
probabilidade de permanência de alunos do sexo feminino, o que permite focar ações assistenciais para garantir a permanência sobre os alunos do sexo masculino.

Segundo a IV Pesquisa Nacional sobre o perfil socioeconômico e cultural dos estudantes de graduação, realizada em 2014 (FONAPRACE, 2016), a taxa de participação do sexo feminino é maior do que a taxa de participação do sexo masculino, estabelecendo-se percentuais de 52,3\% e 47,4\% respectivamente. Não obstante, nas regiões Centro Oeste, Nordeste e Norte tenha ocorrido sensível redução da participação feminina no nível superior. Desse modo, os resultados obtidos corroboram os dados do FONAPRACE (2016).

Entretanto, conforme Barreto (2014, p. 12) este cenário de ocupação majoritária das mulheres no nível superior, "não afasta as distorções de gênero que, articuladas a outros vetores de desigualdade social, como raça/etnia, ainda estão presentes e limitam a equidade na distribuição de oportunidades". Não obstante, outras pesquisas divulgadas por órgãos oficiais como a análise "Estatística de Gênero (IBGE, 2014)" apontam possíveis causas para essa disparidade da ocupação majoritária de mulheres no ensino superior, tanto em relação ao ingresso quanto a menor permanência do sexo masculino, afirmando que esse conjunto pode ser "resultado da entrada precoce de rapazes no mercado de trabalho, o que dificultaria a conciliação entre o emprego e a frequência escolar" (BARRETO, 2014, p. 12).

O Gráfico 2 revela a taxa de permanência entre os sexos, por curso. De um modo geral, o Gráfico 1 já mostrara que a taxa geral de permanência das mulheres foi mais alta que a dos homens. A análise por curso, apresentada no Gráfico 2, revela que apenas no curso de Tecnologia em Irrigação e Drenagem (TID) a taxa de permanência dos homens foi maior do que a das mulheres. Nos cursos de Química e de Serviço Social, as taxas de permanência das mulheres foram maiores, com $54,5 \%$ e $48,1 \%$, respectivamente. No curso de TID, a taxa de permanência dos homens foi maior em $6,2 \%$ do que a taxa de permanência das mulheres.

\section{Gráfico 2- Taxa de permanência por sexo e por cursos de graduação do IFCE campus Iguatu}

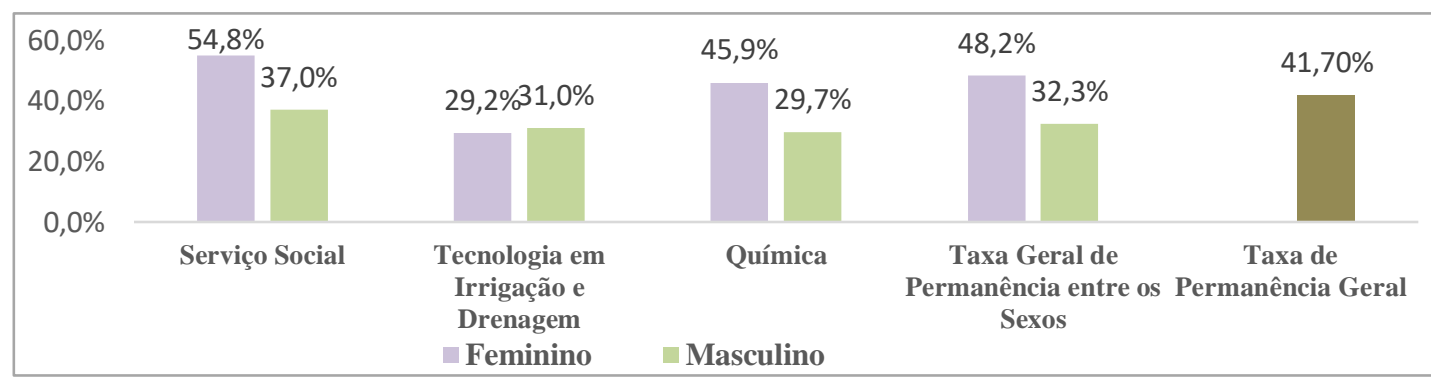

Fonte: Elaborado pelos autores. Dados do Q-Acadêmico do IFCE. 2018. 
Observa-se ainda, mediante o Gráfico 2, que quando se compara a taxa geral de permanência entre os sexos em relação à taxa geral de permanência entre os sexos, constata-se que, apenas o curso de Serviço Social apresenta maior taxa de permanência tanto entre o sexo feminino $(54,8 \%)$ quanto entre o masculino (37\%), como também em relação a taxa geral de permanência entre os sexos feminino $(48,2 \%)$ e masculino $(32,3 \%)$. Os outros dois cursos apresentam taxas de permanência entre os sexos inferior à taxa geral de permanência entre os sexos, revelando que a taxa de permanência deste curso foi a mais elevada no campus de Iguatu.

\section{Auxílios estudantis e permanência no contexto do IFCE campus Iguatu}

Como notado anteriormente, os auxílios no IFCE dividem-se em universais e específicos. No contexto do IFCE, campus Iguatu, são ofertados oito auxílios pecuniários, sendo três do grupo de auxílios universais e cinco do grupo de auxílios aos estudantes em situação de vulnerabilidade social.

O Auxílio Acadêmico (subsidia a participação estudantil em evento acadêmico e sócioestudantil), o Auxílio Pré-Embarque Internacional (subsidia as despesas de discentes no processo de intercâmbio internacional) e o Auxílio Visitas e Viagens Técnicas (subsidia a despesas discentes advindas da participação em visitas/viagens técnicas) compõem o grupo de auxílios universais.

O grupo de auxílios específicos ofertados no campus Iguatu é composto pelo Auxílio Moradia (subsidia despesas estudantis com moradia de estudantes oriundos de regiões distantes da sede do campus), o Auxílio Transporte (subsidia despesas com deslocamento diário de estudantes até o campus), o Auxílio Discente Pai/Mãe (subsidia despesas de estudantes que tenham filhos de até doze anos ou com deficiência), o Auxílio Formação (destina-se a inserir estudantes em setores de pesquisa, ensino e/ou extensão com vistas a formação integral), e o Auxílio Óculos (subsidia despesa com óculos ou lentes de estudantes com dificuldade visual).

O grupo dos auxílios específicos é destinado prioritariamente aos estudantes em situação de vulnerabilidade socioeconômica, com renda familiar per capita de até um salário mínimo e meio. Sobre esse corte socioeconômico, Souza (2017) ponderou que deve haver uma análise socioeconômica mais acurada, para a concessão dos auxílios, ressaltando que não se deve restringir unicamente à aferição da renda per capita, e acrescenta que:

[...] a esta análise é acrescido um exame dos condicionantes sociais, em que se verificam: a situação de moradia, trabalho, número de filhos, despesas familiares, origem escolar, recebimento de benefício de outros programas sociais, comunidade em desvantagem social, além de fatores relacionados: à deficiência do estudante ou de membros da família, doenças crônicas, gênero, cor/etnia, fragilidade de vínculos 
familiares, estudante em situação de risco de diferentes ordens, desde relacionada ao local de habitação à violência intrafamiliar (SOUZA, 2017, p. 143).

Associado aos critérios para acesso a esses auxílios os estudantes beneficiários tem como condicionalidade manter a frequência regular e não reprovar mais que duas disciplinas por semestre. Sobre essas condicionalidades concordamos com Souza (2017, p. 157-158), quando esta assevera:

Esta é uma realidade que se contrapõe à perspectiva da universalidade de direitos, pois se utiliza de mecanismos que articulam condição socioeconômica a critérios meritocráticos para o alcance da bolsa, aliados a contrapartidas, que se não concretizadas cumprem um papel punitivo de cancelamento. Esta forma de compreensão do que é viabilizar permanência na escola enquadra a assistência estudantil em uma lógica em que são selecionados os vulneráveis com o melhor desempenho.

Souza (2017) arremata o seu posicionamento acentuando certa incoerência dessas ações "pois une em um mesmo programa o mérito intelectual com o demérito social, deslocando, além disso, a assistência estudantil para a esfera da monetarização" (p. 158). Souza realça que a Assistência Estudantil não deve ser compreendida apenas na sua dimensão financeira,

[...] pois, além de propiciar mecanismos de desenvolvimento da aprendizagem, também tem que prezar pelo bem-estar e qualidade de vida do estudante, prevenindo condições de risco, fomentando a participação em todos os espaços do Instituto e, para além dele, como partícipe das relações sociais, que se desenvolvem em sociedade, tendo condições de exercitar, com consciência, a sua identidade como ser social (SOUZA, 2017, p. 148-149).

Cabe lembrar que os auxílios estudantis garantem a permanência a partir do apoio monetário que subsidia despesas discentes. Este tipo de apoio fundamenta-se na necessidade mais elencada por estudantes de graduação, consoante a pesquisa realizada pelo Fórum Nacional de Pró-Reitores de Assuntos Estudantis, que se intitulou "IV Pesquisa do Perfil Socioeconômico e Cultural dos Estudantes de Graduação das Instituições Federais de Ensino Superior Brasileiras" (FONAPRACE, 2016).

Entretanto, a permanência escolar é perpassada por outras inúmeras dificuldades. De acordo com a pesquisa supracitada, pode-se realçar as dez principais elencadas pelos estudantes: dificuldades financeiras $(42,21 \%)$, carga horária excessiva de trabalhos estudantis $(31,14 \%)$, falta de disciplina/hábito de estudo (28,78\%), adaptação a novas situações como cidade, moradia distância da família etc. $(21,85 \%)$, relação professor(a) - estudante $(19,8 \%)$, dificuldade de acesso a materiais/meios de estudo (18,33\%), relacionamento familiar $(18,29 \%)$, relacionamento social/interpessoal $(17,66 \%)$, carga horária excessiva de trabalho $(17,45 \%)$, dificuldades de aprendizado (16,22\%) (FONAPRACE, 2016). 
Segundo Recktenvald, Mattei e Pereira (2018) considerando as dificuldades de permanência enfrentadas pelos estudantes, o FONAPRACE luta pela ampliação nos investimentos do PNAES, porque entende que a permanência não é uma questão puramente financeira.

Nas seções que seguem, é possível constatar que mesmo tendo em sua forma todas as contradições que lhe são peculiares, os auxílios estudantis compõem um dos mecanismos de garantia da permanência estudantil, uma vez que possibilitam aos estudantes beneficiários o acesso ao custeio de despesas advindas do ingresso no curso, como moradia, transporte ou com filhos.

\subsection{Beneficiários e não beneficiários no retrato da permanência estudantil}

A comparação entre estudantes beneficiários e não beneficiários de auxílios pecuniários da assistência estudantil tem sido cada vez mais recorrente no cenário acadêmico brasileiro. Nessa direção, o estudo de Cavalcanti (2016) buscou avaliar o Programa de Auxílio Estudantil da UTFPR - Câmpus Curitiba, por meio de análise comparativa entre o coeficiente acadêmico e de permanência dos estudantes bolsistas do Programa em relação aos demais estudantes da Universidade. A autora constatou, em seus resultados, tanto um rendimento acadêmico superior dos beneficiários, em média 10,5\% maior em relação aos não beneficiários, quanto uma taxa de permanência dos beneficiários $(37,08 \%)$ em relação aos não beneficiários, indicando assim, que o programa de auxílios pecuniários tem impactos significativos tanto na permanência quanto no sucesso escolar.

A Tabela 2 apresenta o volume dos três tipos de auxílios em análise concedido no período de 2011 a 2015 considerando os três cursos de graduação do IFCE campus Iguatu.

Tabela 2 - Quantidade de auxílios permanentes concedidos de 2011 a 2015

\begin{tabular}{lcc}
\hline \multicolumn{1}{c}{ Tipo de auxílio } & Quantidade & \% \\
\hline Auxílio moradia & 152 & $45,9 \%$ \\
Auxílio transporte & 150 & $45,3 \%$ \\
Auxílio discente pai/mãe & 29 & $8,8 \%$ \\
\hline Total & 331 & $100 \%$ \\
\hline
\end{tabular}

Fonte: Elaborado pelos autores. Dados do setor de Serviço Social do IFCE -campus Iguatu, 2018 
Consoante os dados da Tabela 2, de 2011 a 2015, o tipo de auxílio que teve maior número de beneficiários ${ }^{1}$ foi o Auxílio Moradia (152) seguido pelo Auxílio Transporte (150) e pelo Auxílio Discente Pai/Mãe (29).

A Tabela 3 estratifica os 331 beneficiários de pelo menos um dos três tipos de auxílios nos três cursos de graduação do IFCE campus Iguatu, no período de 2011 a 2015, identificados na Tabela 2, por semestre.

Tabela 3 - Taxa de Ingressos Beneficiários dos três auxílios permanentes do IFCE campus Iguatu por semestre (2011 a 2015)

\begin{tabular}{|c|c|c|c|c|c|c|c|c|c|c|c|}
\hline & 2011.1 & 2011.2 & 2012.1 & 2012.2 & 2013.1 & 2013.2 & 2014.1 & 2014.2 & 2015.1 & 2015.2 & Total \\
\hline $\begin{array}{c}\mathrm{N}^{\circ} \\
\text { Ingressantes }\end{array}$ & 106 & 83 & 104 & 103 & 120 & 108 & 96 & 72 & 119 & 99 & 1010 \\
\hline $\begin{array}{c}\mathrm{N}^{\mathrm{o}} \\
\text { Beneficiário } \\
\mathrm{S} \\
\end{array}$ & 31 & 24 & 35 & 29 & 41 & 36 & 44 & 34 & 34 & 23 & 331 \\
\hline $\begin{array}{c}\text { Tx. } \\
\text { Beneficiário } \\
\text { s }\end{array}$ & $29,2 \%$ & $28,2 \%$ & $33,7 \%$ & $28,1 \%$ & $34,1 \%$ & $33,3 \%$ & $45,8 \%$ & $47,2 \%$ & $28,6 \%$ & $23.3 \%$ & $\begin{array}{c}32,8 \\
\%\end{array}$ \\
\hline
\end{tabular}

Fonte: Elaborado pelos autores, a partir dos dados disponíveis no setor de Serviço Social do IFCE campus Iguatu. 2018.

A Tabela 3 mostra que o semestre que teve maior número de ingressantes beneficiários foi 2014.1 (44 beneficiários) e o semestre com menor número de ingressantes beneficiários foi o semestre 2015.2 (23 beneficiários). Ao se considerar o total de beneficiários por ano, observase que o ano com maior número absoluto de beneficiários foi 2014 (78 beneficiários) e o ano com menor número absoluto foi 2011 (apenas 55 beneficiários).

A taxa de beneficiários, composta pelo número total de beneficiários da assistência, em relação ao número total de ingressantes em cada semestre foi maior nos semestres 2014.2, 2014.1 e 2013.1 nos quais 47,2\%, 45,8\% e 34,1\% dos estudantes que ingressaram foram beneficiários da assistência estudantil, respectivamente. A menor taxa de beneficiários ocorreu nos semestres 2015.2, 2012.2 e 2011.2, quando apenas 23,3\%, 28,1\% e 28,2\% dos alunos ingressantes foram assistidos por benefícios, respectivamente, conforme revela a Tabela 3.

Ainda de acordo com a Tabela 3, houve uma média de beneficiamento entre os estudantes que ingressaram no período 2011 a 2015 de 32,8\%, ou seja, considerando a soma da quantidade de ingressantes do período, pela soma do número de beneficiários do período,

\footnotetext{
${ }^{1} \mathrm{O}$ número de beneficiários anual ou semestral refere-se sempre aos estudantes que ingressaram no semestre ou ano e foram beneficiados. A condição de beneficiário é analisada em relação ano de ingresso.
} 
constata-se que $32,8 \%$ do total de ingressos foram beneficiados com pelo menos um dos três tipos de auxílios em análise. Cinco semestres estiveram abaixo desta média de 32,8\% e cinco semestres estiveram acima desta mesma média.

O Gráfico 3 mostra o percentual de beneficiários da assistência no período de 2011 a 2015, dos três cursos, por sexo. A Taxa de Beneficiários por sexo em cada curso foi calculada a partir do número de estudantes beneficiários de cada sexo, em relação ao total de estudantes beneficiários em cada curso, de ambos os sexos, em todo o período objeto da análise.

\section{Gráfico 3- Taxa geral de beneficiários dos três auxílios permanentes do IFCE campus Iguatu de 2011 a 2015 - por sexo e curso}

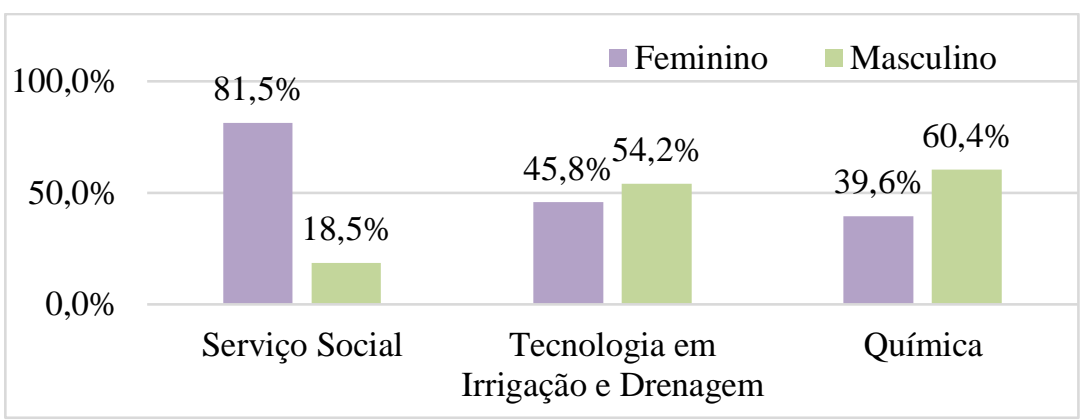

Fonte: Elaborado pelo autores a partir de dados do Setor de Serviço Social do IFCE campus Iguatu, 2018.

O Gráfico 3 mostra que, do total de estudantes beneficiários do curso de Serviço Social em pelo menos um dos três tipos de auxílios permanentes, $81,5 \%$ são do sexo feminino e apenas 18,5\% do sexo masculino. No curso de Química, a maioria dos beneficiários também é do sexo feminino (60,4\%), em relação ao sexo masculino (39,6\%). No curso de Irrigação e Drenagem o número de beneficiários do sexo masculino $(54,2 \%)$ supera o número de beneficiários do sexo feminino $(45,8 \%)$.

A Tabela 4 mostra o volume de beneficiários por tipo de auxílio e por curso de graduação, no período de 2011 a 2015, no IFCE campus Iguatu. De acordo com ela, o curso com o maior número de beneficiários de auxílios foi Serviço Social (143), seguido pelo curso de Tecnologia em Irrigação e Drenagem (98) e, por último, o Curso de Química (90). 
Tabela 4 - Número de Beneficiários e Taxa de Permanência dos Beneficiários por curso e Tipo de Auxílio dos cursos de graduação do IFCE campus Iguatu, de 2011 a 2015

\begin{tabular}{|c|c|c|c|c|c|c|}
\hline \multirow{2}{*}{$\begin{array}{l}\text { Tipo de } \\
\text { auxílio }\end{array}$} & \multicolumn{2}{|c|}{ Serviço Social } & \multicolumn{2}{|c|}{ Química } & \multicolumn{2}{|c|}{$\begin{array}{c}\text { Tecnologia em Irrigação e } \\
\text { Drenagem }\end{array}$} \\
\hline & $\begin{array}{c}\text { No. } \\
\text { beneficiários }\end{array}$ & $\begin{array}{c}\text { Taxa de } \\
\text { permanência }\end{array}$ & $\begin{array}{c}\text { No. } \\
\text { beneficiários }\end{array}$ & $\begin{array}{c}\text { Taxa de } \\
\text { permanência }\end{array}$ & $\begin{array}{c}\text { No. } \\
\text { beneficiários }\end{array}$ & $\begin{array}{l}\text { Taxa de } \\
\text { permanência }\end{array}$ \\
\hline $\begin{array}{l}\text { Auxílio } \\
\text { Moradia }\end{array}$ & 62 & $82,5 \%$ & 48 & $61,9 \%$ & 42 & $66,6 \%$ \\
\hline $\begin{array}{l}\text { Auxílio } \\
\text { Transporte }\end{array}$ & 62 & $75,4 \%$ & 39 & $73,4 \%$ & 49 & $50 \%$ \\
\hline $\begin{array}{l}\text { Auxílio } \\
\text { Discente } \\
\text { pai/mãe }\end{array}$ & 19 & $84,2 \%$ & 3 & $80 \%$ & 7 & $66,7 \%$ \\
\hline $\begin{array}{l}\text { Total de } \\
\text { beneficiários }\end{array}$ & 143 & $79,5 \%$ & 90 & $68,7 \%$ & 98 & $60,2 \%$ \\
\hline
\end{tabular}

Fonte: Setor de Serviço Social do IFCE campus Iguatu, 2018.

Ainda de acordo com a Tabela 4, no curso de Serviço Social, dos 143 beneficiários, 62 são auxílio transporte, 62 são auxílio moradia e 19 são auxílio discente pai mãe. No curso de TID, entre os 98 beneficiários, 42 foram de Auxílio Moradia, 49 do Transporte e 7 do Auxílio Discente Pai/Mãe. Por fim, no curso de Química, entre os 90 beneficiários, 48 foram de auxílio moradia, 39 de transporte e 3 do discente pai/mãe.

O auxílio que tem maior taxa de permanência dos beneficiários é o Auxílio Discente Pai/Mãe, que atinge taxa de permanência de $84,2 \%$ no curso de Serviço Social, $80 \%$ no curso de Química e 66,7\% no curso de Tecnologia em Irrigação e Drenagem. No caso do curso de Química, este é o que tem menor taxa de permanência de beneficiários do auxílio moradia (61,9\%), e o curso de Irrigação é o curso com menor taxa de permanência no caso dos beneficiários do auxílio transporte (50\%). Observa-se que em todos os três tipos de auxílios a menor taxa de permanência dos beneficiados é de 50\%, a qual constitui a realidade do auxílio transporte do curso de Irrigação.

O Gráfico 4 apresenta a taxa de permanência entre os beneficiários (calculou-se, por curso, o número de beneficiários que permaneceu pelo total de estudantes beneficiários), e a taxa de permanência entre os não beneficiários (calculou-se a relação entre a quantidade de estudantes que não foram beneficiados e permaneceram pelo total de estudantes não beneficiados). 


\section{Gráfico 4 - Taxa de permanência entre beneficiários e não beneficiários de auxílios no IFCE campus Iguatu por curso - 2011 a 2015}

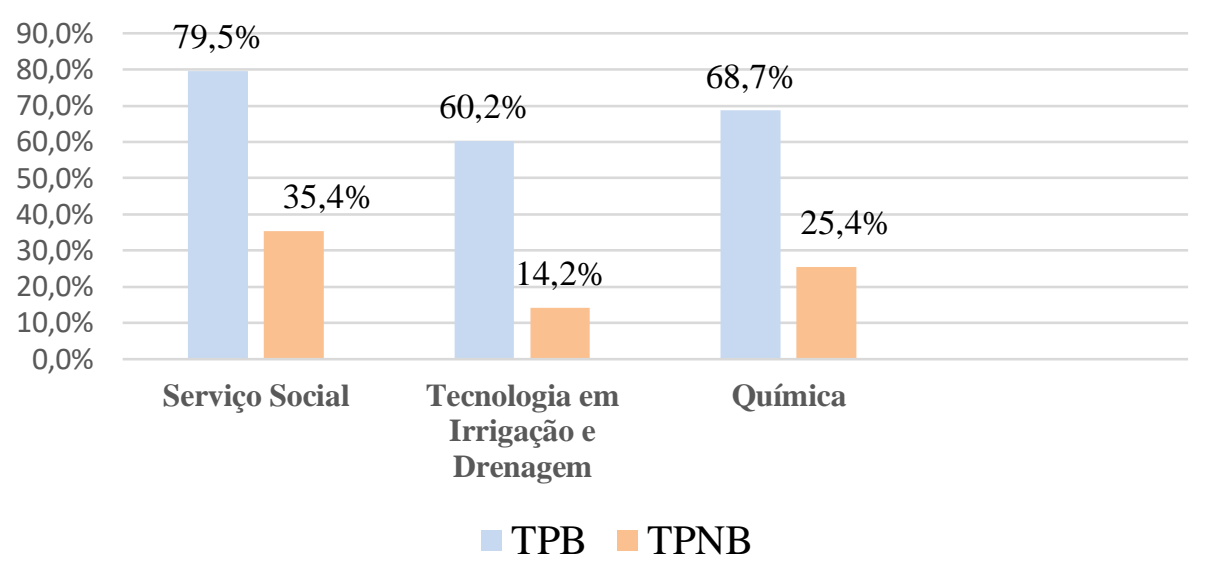

Fonte: Elaborado pelos autores partir de dados do Setor de Serviço Social e no Sistema acadêmico do IFCE campus Iguatu, 2018.

O Gráfico 4 mostra que o curso de Serviço Social possui a melhor taxa de permanência, tanto entre os beneficiários como entre os não beneficiários da Assistência Estudantil, e que o Curso de Tecnologia em Irrigação e Drenagem teve a menor taxa de permanência, tanto entre os beneficiários quanto relação aos alunos não beneficiários da Assistência Estudantil.

Considerando os grupos dos beneficiários e dos não beneficiários, observou-se que as melhores taxas de permanência foram dos alunos beneficiários da Assistência, em todos os cursos. Constata-se que os estudantes beneficiários da Assistência Estudantil permaneceram mais do que os estudantes não beneficiários, corroborando com os resultados da pesquisa de Cavalcanti (2016), realizada na UTFPR.

\section{Considerações finais}

A execução desta pesquisa permitiu identificar que o contexto da permanência dos estudantes de graduação do IFCE campus Iguatu retrata em muitos aspectos o contexto nacional, retratando situações nas quais o acesso aos auxílios estudantis têm ocasionado maior taxa de permanência dos beneficiários em relação aos estudantes não beneficiários.

Constatou-se que o ensino superior do IFCE campus Iguatu é perpassado por uma realidade em que ingressam mais mulheres do que homens, e de forma geral, também permanecem mais mulheres do que homens, embora curso essa realidade se diferencie curso a curso. Por exemplo, os estudantes do sexo feminino permanecem mais no curso de Serviço Social, em seguida no curso de Química e depois no de Irrigação, com taxas em torno de 54,8\%, 
$45,9 \%$ e $29,2 \%$, respectivamente. Enquanto isso, em relação ao sexo masculino, observa-se que este permanece mais no curso de Serviço Social, seguido pelo curso de Irrigação e depois Química, com taxas de 37\%, 31\% e 29,7\%, respectivamente.

Os auxílios estudantis indicam uma considerável repercussão da taxa de acesso à assistência estudantil sobre a taxa de permanência, uma vez que para todos os cursos analisados, os estudantes beneficiários permanecem mais do que os não beneficiários. Observa-se, que a taxa de permanência entre beneficiários por curso, supera inclusive a taxa geral de permanência que é 41, 7\%. É possível considerar que isso pode se dar devido ao fato dos auxílios estudantis atuarem sobre as dificuldades financeiras dos discentes, uma vez que estas são apontadas na pesquisa nacional realizada pelo FONAPRACE (2016) como o elemento que mais dificulta a permanência escolar dentre tantos outros existentes.

Se os auxílios forem considerados como um dos requisitos essenciais para a permanência estudantil, pode-se inferir que o curso que tem estudantes com melhores condições de permanecer sem acessar esses auxílios é o curso de Serviço Social, pois de todos os cursos ele é o que tem a maior taxa de permanência entre os não beneficiários $(35,4 \%)$, embora consideravelmente inferior à taxa de permanência entre os beneficiários do mesmo curso $(79,5 \%)$. E o curso com estudantes com menores condições de permanência de estudantes sem acessar os auxílios em questão é o curso de Irrigação, cujo mesmo tem a menor taxa de permanência entre os não beneficiários $(14,2 \%)$.

A permanência estudantil é refletida também a partir de condições sociais, econômicas e educacionais antecedentes ao período de ingresso na graduação, uma vez que são essas condições prévias que dirão o perfil dos estudantes e inclusive a ocupação de determinadas áreas de graduação.

Considera-se, portanto, de suma importância o desenvolvimento de pesquisas futuras que observem o perfil social, econômico e educacional dos estudantes por curso, para ser possível traçar estratégias e entender qual o perfil dos estudantes de cada curso e a relação desse perfil com os índices de abandono e permanência.

No entanto, conforme apontam as observações de campo, além dos fatores anteriormente apontados pela IV Pesquisa nacional sobre o perfil socioeconômico e cultural dos estudantes de graduação, realizada em 2014, outro fator que muito influencia na não permanência escolar é a falta de identificação com o curso de matrícula, ou seja, este fator também pode ser encarado como uma das causas para a baixa permanência, tanto entre os beneficiários quanto entre os não beneficiários do curso de Irrigação. 
Considerando a limitação deste trabalho em ter analisado somente os beneficiários dos três auxílios pecuniários em questão, frente a uma política de assistência estudantil densa e complexa, composta por variados programas e serviços, nota-se a necessidade de pesquisas futuras investigarem a efetividade dessa política considerando a realidade desses demais programas e serviços existentes. Faz-se necessário, portanto, mais investigações que observem o comportamento orçamentário e o comportamento da demanda pela política ao longo dos anos, cujo objetivo seja perceber as necessidades reais postas, as necessidades atendidas e não atendidas.

Ademais, é importante traçar um perfil dos públicos específicos de discentes quanto à política em questão, ou seja, os cotistas sociais e raciais, por exemplo, devem ser abordados quanto às suas dificuldades de permanência em relação ao acesso que tem a política em questão. Ficam os desafios imensos e inúmeros para avaliações futuras no campo da Política de Assistência Estudantil, considerando-a como possibilidade real e efetiva de acesso ao direito à educação, a partir do acesso ao direito de permanecer na escola.

Para finalizar, recorre-se a uma sábia frase, proferida por um dos maiores expoentes do Século XX, nos campos da Psicologia e da Educação, o biólogo e educador suíço Jean William Fritz Piaget, que, certa feita asseverou: o principal objetivo da educação é criar pessoas capazes de fazer coisas novas e não simplesmente repetir o que outras gerações fizeram.

\section{Referências}

ANDRADE, Ana Maria Jung de; TEIXEIRA, Marco Antônio Pereira. Áreas da política de assistência estudantil: relação com desempenho acadêmico, permanência e desenvolvimento psicossocial de universitários. Avaliação, Campinas; Sorocaba, SP, v. 22, n. 2, p. 512-528, jul. 2017. Disponível em: http://www.scielo.br/scielo.php?pid=S1414$40772017000200512 \&$ script $=$ sci abstract\&tlng=pt. Acesso em: 6 fev. 2019.

ANDRIOLA, Wagner Bandeira. Evaluación: lavía para lacalidad. Ensaio, Rio de Janeiro, v. 7, n. 25, p. 355-368, 1999.

ANDRIOLA, Wagner Bandeira. Avaliação: múltiplos olhares em torno da Educação. Fortaleza: Editora da UFC, 2005.

ANDRIOLA, Wagner Bandeira. Propostas estatais voltadas à avaliação do Ensino Superior brasileiro: breve retrospectiva histórica do período 1983-2008. Revista Electrónica Iberoamericana Sobre Calidad, Eficacia y Cambio en Educación, Madrid, v. 6, p. 127 148, 2008. Disponível em: https://www.redalyc.org/pdf/551/55160408.pdf. Acesso em: 6 fev. 2019. 
ANDRIOLA, Wagner Bandeira; SULIANO, Daniele Cirilo. Avaliação dos impactos sociais oriundos da interiorização da Universidade Federal do Ceará (UFC). Rev. Bras. Estud.

Pedagog., Brasília, v. 96, n. 243, p. 282-298, ago. 2015.

ARAÚJO, Adriana Castro; ANDRIOLA, Wagner Bandeira; COELHO, Afrânio de Araújo. Programa institucional de bolsa de iniciação à docência (PIBID): desempenho de bolsistas versus não bolsistas. Educ. rev., Belo Horizonte, v. 34, 2018. Disponível em:

http://www.scielo.br/scielo.php?script=sci_abstract\&pid=S0102-

46982018000100112\&lng=en\&nrm=iso\&tlng=pt. Acesso em: 6 fev. 2019.

BARRETO, Andreia. A mulher no ensino superior - distribuição e representatividade.

Cadernos do GEA, Rio de Janeiro, n. 6, jul./dez. 2014. Disponível em:

http://flacso.org.br/files/2016/04/caderno_gea_n6_digitalfinal.pdf. Acesso em: 6 fev. 2019.

BRASIL. Decreto no 7.234 de 19 de Julho de 2010. Regulamenta o Programa Nacional de Assistência Estudantil - PNAES. 2010. Disponível em:

http://www.planalto.gov.br/ccivil_03/_Ato2007-2010/2010/Decreto/D7234.htm. Acesso em: 20 jan. 2016.

CAVALCANTI, Rosangela Wojdela. Avaliação da eficácia do Programa de Auxílio

Estudantil na Universidade Tecnológica Federal do Paraná - Câmpus Curitiba. 2016.

Dissertação (Mestrado) - Universidade Tecnológica Federal do Paraná, Curitiba, 2016.

DIAS SOBRINHO, José. Democratização, qualidade e crise da educação superior: faces da exclusão e limites da inclusão. Educ. Soc. Campinas, v. 31, n. 113, p. 1223-1245, out./dez. 2010.

DUMARESQ, Zandra Maria Mendes. Análise da política de Assistência Estudantil no âmbito do Instituto Federal do Ceará - campus de Fortaleza sob o olhar dos discentes. Dissertação (Mestrado) - Pró-Reitoria de Pesquisa e Pós-Graduação, Universidade Federal do Ceará, Fortaleza, 2014. Disponível em:

http://www.repositorio.ufc.br/bitstream/riufc/8995/1/2014_dis_zmmdumaresq.pdf. Acesso em: 6 fev. 2019.

FONAPRACE. FÓRUM NACIONAL DE PRÓ-REITORES DE ASSUNTOS COMUNITÁRIOS E ESTUDANTIS. IV Pesquisa do Perfil Socioeconômico e Cultural dos Estudantes de Graduação das Instituições Federais de Ensino Superior brasileiras. Uberlândia, 2016. Disponível em: http://www.andifes.org.br/wpcontent/uploads/2017/11/Pesquisa-de-Perfil-dos-Graduanso-das-IFES_2014.pdf. Acesso em: 6 fev. 2019.

IBGE. ISNTITUTO BRASILEIRO DE GEOGRAFIA E ESTATÍSTICA. Estatísticas de Gênero: indicadores sociais das mulheres no Brasil. Brasília, 2014. Disponível em: https://biblioteca.ibge.gov.br/visualizacao/livros/liv101551_informativo.pdf. Acesso em: 6 fev. 2019.

IFCE. INSTITUTO FEDERAL DO CEARÁ. Resolução 024, de 22 de junho de 2015. Trata da aprovação da Política de Assistência Estudantil do IFCE. Fortaleza, 2015. Disponível em: https://ifce.edu.br/espaco-estudante/assistencia-estudantil/arquivos/regulamento-da-politicade-assistencia-estudantil-do-ifce.pdf. Acesso em: 7 jan. 2018. 
IFCE. INSTITUTO FEDERAL DO CEARÁ. Resolução 052, de 24 de outubro de 2016. Trata da aprovação do Regulamento de Concessão de Auxílios Estudantis no IFCE. Fortaleza, 2016. Disponível em: https://ifce.edu.br/espaco-estudante/assistenciaestudantil/arquivos/resolucao-no-052-2016.pdf/view. Acesso em: 7 jan. 2018.

LORENZET, Deloíze. Expansão e democratização da educação superior brasileira: a oferta de licenciaturas nos Institutos Federais no Estado do Rio Grande do Sul. Tese (Doutorado) - Faculdade de Educação, Programa de Pós-graduação em Educação, Universidade Federal do Rio Grande do Sul, Porto Alegre, 2017. Disponível em: https://lume.ufrgs.br/handle/10183/151686. Acesso em: 6 fev. 2019.

MARCONI, Marina de Andrade; LAKATOS, Eva Maria. Fundamentos de metodologia Científica. 7. ed. São Paulo: Atlas, 2010.

OTRANTO, Célia Regina. A reforma da educação profissional e seus reflexos na educação superior. Revista Temas em Educação, João Pessoa, v. 22, n. 2, p. 122-135, jul./dez. 2013. Disponível em: http://periodicos.ufpb.br/index.php/rteo/article/viewFile/17782/10147. Acesso em: 6 fev. 2019.

PINTO, Giselle. A política de assistência estudantil da UFF em duas faces: a institucionalidade dos processos e as perspectivas da demanda estudantil. Tese (Doutorado) Pontifícia Universidade Católica do Rio de Janeiro, 2015. Disponível em:

https://www.maxwell.vrac.puc-rio.br/acessoConteudo.php?nrseqoco=85843. Acesso em: 6 fev. 2019.

RAMALHO, Ludimila Eleonora Gomes. Abordagem avaliativa da política de assistência estudantil em uma instituição de ensino profissional. Dissertação (Mestrado Profissional em Gestão e Avaliação da Educação Pública) - Faculdade de Educação, Universidade Federal de Juiz de Fora, 2013. Disponível em: http://www.mestrado.caedufjf.net/wpcontent/uploads/2014/02/dissertacao-2011-ludmila-eleonora-gomes-ramalho.pdf. Acesso em: 6 fev. 2019.

RECKTENVALD, Marcelo; MATTEI, Lauro; PEREIRA, Vilmar Alves. Avaliando o Programa Nacional de Assistência Estudantil (PNAES) sob a ótica das epistemologias. Avaliação, Campinas; Sorocaba, v. 23, n. 2, p. 405-423, jul. 2018. Disponível em: http://www.scielo.br/scielo.php?pid=S141440772018000200405\&script=sci abstract\&tlng=pt. Acesso em: 6 fev. 2019.

SILVA FILHO, Roberto Leal Lobo et al. A evasão no ensino superior brasileiro. Cadernos de Pesquisa, São Paulo, v. 37, n. 132, p. 641-659, set./dez. 2007.

SOUZA, Jacqueline Domiense Almeida de. Na travessia: assistência estudantil da educação Profissional. As interfaces das políticas de assistência social e educação. Dissertação (Mestrado em Política Social) - Universidade de Brasília, 2017. Disponível em: http://repositorio.unb.br/handle/10482/23610. Acesso em: 6 fev. 2019. 